\title{
A AQUISIÇÃO DE TERRAS BRASILEIRAS POR ESTRANGEIROS PARA AS PRÁTICAS DA ECOLOGIA DE LIVRE MERCADO
}

\author{
THE BRAZILIAN LAND ACQUISITION BY FOREIGNERS FOR FREE MARKET \\ ENVIRONMENTALISM PRACTICES
}

\author{
Pedro Felippe Tayer Neto* \\ João da Cruz Gonçalves Neto** \\ Cristiane Derani ${ }^{* * *}$
}

\begin{abstract}
Resumo
O objetivo deste artigo é demonstrar como as práticas da ecologia de livre mercado seriam estimuladas pela mitigação das restrições impostas pela Lei 5.709/71 à aquisição de terras brasileiras por estrangeiros. Pretende-se também expor as consequências negativas de cunho ecológico, econômico e social destas práticas, como a inviabilização da reforma agrária, a formação de grandes latifúndios improdutivos e a intensificação de um mercado de compra e venda de direitos de poluir e desmatar.
\end{abstract}

Palavras Chave: Direito agrário. Ecologia de livre mercado. Aquisição de terras por estrangeiros.

\begin{abstract}
This article's purpose is to demonstrate how the free market environmentalism practices would be stimulated by mitigating the restrictions to the aquisition of brazilian land by foreigners imposed by the Law 5.709/71. It will also be exposed the ecological, economical and social negative consequences, such as the agrarian reform impracticability, the large unproductive landholdings formation and the intensification of a market for buying and selling rights to pollute and deforest.
\end{abstract}

Keywords: Agrarian Law. Free Market Environmentalism. Land Acquisition by Foreigners.

* Possui graduação em Direito pela Universidade Federal de Uberlândia (2010), especialização em Direito Constitucional pela Universidade Federal de Goiás (UFG) e mestrado em Direito Agrário pela Universidade Federal de Goiás (2014). Atualmente é professor da Faculdade Sul-Americana e advogado - Ordem dos Advogados do Brasil - Seção de Goiás. , atuando principalmente nos seguintes temas: Direito Agrário, Direito Constitucional e Teoria do Direito.

** Possui graduação em Filosofia pela Universidade Federal de Goiás (1989), graduação em Direito pela Universidade Federal de Goiás (1998), mestrado em Filosofia pela Universidade Federal de Goiás (2000) e doutorado em Filosofia pela Pontifícia Universidade Católica do Rio Grande do Sul (2006). Atualmente é professor adjunto II na Universidade Federal de Goiás. Tem experiência na área de Direito, com ênfase em Filosofia do Direito, atuando principalmente nos seguintes temas: direito e arte, teorias da justiça, conflitos agrário-ambientais e direitos humanos.

*** Possui graduação em Direito pela Universidade de São Paulo (1988) e doutorado em Direito pela Universidade de São Paulo (1996). Estudos de doutorado (bolsa CNpq) na J.W.Goethe Universitaet, Frankfurt. Pós-doutorado na Ecole des Hautes Etudes en Sciences Sociales, Paris. Livre-docente pela Universidade de São Paulo. Foi professora associada da Universidade de São Paulo, professora titular do mestrado em Direito Ambiental da Universidade do Estado do Amazonas, professora do Mestrado da Universidade Católica de Santos, professora convidada da universidade Pablo d'Olavide, Sevilha. Atualmente é professora da Universidade Federal de Santa Catarina. Dirige o grupo de pesquisa Estudos Avançados em Meio Ambiente e Economia no direito Internacional. 


\section{Introdução}

O presidente da Associação Brasileira de Reforma Agrária (ABRA), Gerson Teixeira, recentemente concedeu uma entrevista à Rede Brasil Atual (TOLEDO: 2012; p.1-3) na qual demonstrava que as crescentes pressões para a liberação da aquisição de terras brasileiras por estrangeiros estavam lhe causando certo desconforto. Na visão do entrevistado, o Brasil estaria sofrendo sério risco de se tornar um grande latifúndio improdutivo, já que o país, de fauna e flora reconhecidamente ricas, atraía os olhares dos ecologistas de mercado. Mas, o que seriam estes ecologistas de livre mercado? Quais são as suas práticas? E ainda, porque existe tanta pressão para mudar o regime de aquisição de terras brasileiras? Estas foram as principais indagações que motivaram o presente escrito.

Na primeira parte deste artigo, pretende-se elaborar uma visão geral acerca da ecologia de livre mercado, uma corrente de pensamento que nasceu entre o final da década de 60 e o início da década de 70, mas que foi ganhar força e visibilidade apenas na década de 90. Pretende-se abordar não apenas as construções teóricas, mas também as soluções práticas que deram visibilidade aos seus adeptos.

Em um segundo momento, pretende-se fazer um apanhado geral do regime jurídico da aquisição de terras por estrangeiros no Brasil. A evolução histórica do instituto na legislação e as principais restrições impostas pelo sistema jurídico brasileiro aos adquirentes estrangeiros. Dar-se-á atenção especial ao papel desempenhado pela Advocacia-Geral da União (AGU) no caloroso debate jurídico que vem acontecendo.

Em um último momento, pretende-se demonstrar como uma maleabilização das restrições impostas à aquisição de terras por pessoas físicas ou jurídicas estrangeiras facilitaria a utilização das terras brasileiras para as práticas da ecologia de livre mercado, o que acarretaria consequências negativas ao Brasil, tanto do ponto de vista ecológico como do econômico e do social, inviabilizando as políticas de reforma agrária, estimulando a formação de grandes latifúndios de "proteção ambiental" e a intensificação de um mercado de compra e venda de direitos de desmatar e poluir. 


\title{
A AQUISIÇÃO DE TERRAS BRASILEIRAS POR ESTRANGEIROS [...]
}

\section{Uma Ecologia de Livre Mercado?}

\author{
1.1 A Tragédia dos Bens Comuns
}

O escrito de Garrett Hardin (1968: p.1243-1248) intitulado The tragedy of the commons é geralmente tido como o marco inicial da construção teórica de uma Ecologia de Livre Mercado. O autor, que dedicou boa parte de sua obra denunciando as mazelas de uma superpopulação (overpopulation) humana, tenta desconstruir ${ }^{1}$ uma noção comum à época: a ideia de que o crescimento populacional humano não seria um problema preocupante, uma vez que o aumento das populações naturalmente atingiria um ponto de equilíbrio, obedecendo, ainda que involuntariamente, à teoria da mão invisível, como formulada por Adam Smith.

Se vivemos em um mundo dotado de recursos naturais finitos ${ }^{2}$ e de uma população humana crescente, a conclusão é que a fatia por habitante (per capita share) dos recursos naturais diminui constantemente. Um mundo finito só comportaria uma população também finita ${ }^{3}$. Sendo assim, será que a constante diminuição eventualmente atingiria um patamar ideal, estável, por meio de autorregulação, ou, na realidade, o aumento populacional descontrolado arriscaria, ao mesmo tempo, homem e natureza? Não seria o caso de repensar as liberdades individuais, notadamente a liberdade de procriar? Este é o questionamento proposto por Hardin:

In economic affairs, The Wealth of Nations (1776) popularized the "invisible hand", the idea that an individual who "intends only his own gain," is, as it were, "led by an invisible hand to promote ... the public interest" [...] he contributed to a dominant tendency of thought that has ever since interfered with positive action based on rational analysis, namely, the tendency to assume that decisions reached individually will, in fact, be the best decisions for an entire society. If this assumption is correct it justifies the continuance of our present policy of laissez-faire in reproduction. If the assumption is not correct, we need to reexamine our individual freedoms to see which ones are defensible (HARDIN: 1968; p.1244).

É neste panorama que se dá a tragédia dos bens comuns (commons). Para o autor, o constante aumento populacional cumulado com a progressiva diminuição da fatia per capta dos recursos naturais, levaria o homem, irrestrito em suas liberdades individuais, a arruinar o 
meio ambiente.

O exemplo da tese é bastante conhecido. Hardin (1968; p.1244-1245) convida os leitores a pensar nos bens comuns na figura de uma grande e aberta pastagem. O ser humano, na fábula, seria como um pastor, que, por ser um homem racional, busca sempre o aumento de seus rebanhos. Seu questionamento é relativamente simples: cada animal adicionado à pastagem comum the garantirá a futura fruição individual de uma vantagem. Todavia, os prejuízos do aumento do número de animais, ocasionado pelo elevado número de pastores naquela área (aumento populacional), que desequilibraria a relação entre alimentação do rebanho e "regeneração" do pasto, causando consequências negativas (o sobrepastoreio, ou, até mesmo, o esgotamento dos pastos), seriam compartilhados por todos os pastores de forma idêntica.

Se os benefícios seriam usufruídos individualmente enquanto os malefícios suportados coletivamente entre todos os pastores, não existiria qualquer estímulo para a responsável administração dos pastos. O esgotamento dos bens comuns, desta forma, seria a consequência inarredável de sua própria existência.

A maior contribuição de sua teoria para a ecologia de livre mercado, entretanto, está na solução proposta pelo autor para evitar a tragédia dos bens comuns: a moderação (temperance) na utilização destes bens, que só poderia ser atingida por meio do enfrentamento direto de uma questão moral. Essa moderação, entretanto, não poderia ser imposta de forma eficiente pelo Estado por meio da lei. Por sua própria necessidade de tipificação das condutas vedadas, a lei não conseguiria delimitar todas as formas pelas quais os bens comuns poderiam ser sobreexplorados. A consequência seria a outorga de uma grande margem de atuação (e, porque não, discrição) às agências controladoras (bureaus). Para o autor, tais agências são merecedoras de desconfiança:

Since it is practically impossible to spell out all the conditions under which it is safe to burn trash in the back yard or to run an automobile without smogcontrol, by law we delegate the details to bureaus. The result is administrative law, which is rightly feared for an ancient reason - Quis custodiet ipsos custodes? - "Who shall watch the watchers themselves?" John Adams said that we must have "a government of laws and not men." 
Bureau administrators, trying to evaluate the morality of acts in the total system, are singularly liable to corruption, producing a government by men, not laws (HARDIN: 1968; p. 1245-1246).

Apesar de o escrito de Hardin ter se limitado a defender a ineficiência do Estado e da burocracia estatal em combater o problema do esgotamento ambiental, alguns ecologistas interpretaram sua tese de forma bastante peculiar: frente à inaptidão do poder público em tutelar a questão, incumbiria à iniciativa privada a proteção do meio ambiente. Esta ideia é o embrião de uma ecologia de livre mercado.

A obra de Anderson e Leal (1992; p.49-50) trás um exemplo que traduz com maestria o pensamento. Trata-se do caso Ravenna Park. Contam os autores que em meados de 1887, um Senhor e Senhora Beck compraram diversos pedaços de terras nos arredores de Seattle, no estado de Washington, Estados Unidos da América, nos quais existiam abetos gigantescos, uma espécie de pinheiro, que chegavam a mais de 120 metros de altura. As áreas foram transformadas em um parque, o Ravenna Park, e, apesar de ser privado e de cobrar uma taxa para a entrada, prontamente tornou-se popular. "Mesmo com a taxa de admissão, de oito mil a dez mil pessoas visitavam o parque num dia de muito movimento" (ANDERSON; LEAL: 1992; p. 49).

A tragédia começou no início do século XX, quando o aumento das preocupações pela conservação ambiental levou as populações locais a pressionarem os governantes pela compra das áreas do Ravenna Park. Em 1911 o parque foi desapropriado, passando a ser administrado pelo poder público. Pouco tempo depois, os imensos abetos começaram a desaparecer. Os motivos alegados para a derrubada, como averiguados pelos autores, foram os mais diversos: alguns teriam se tornardo um perigo para a população, outros foram supostamente vítimas de uma tempestade de 1925, e, existia também distribuição de culpa para carros e fumaças das chaminés. A verdade é que até o final do ano de 1925 todos os abetos já haviam desaparecido.

Os autores, por sua vez, não demonstram dúvidas quanto ao que ocorreu: “[...] foi a burocracia que destruiu o que os Beck haviam preservado. Os funcionários do parque, tirando vantagens de seu acesso, cortaram as árvores para vender como lenha." 
(ANDERSON; LEAL: 1992; p.50).

O traço marcante da ecologia de mercado é a superação da mera repulsa à ineficiência da burocracia estatal, como se percebia em Hardin, para a centralização da solução da questão ambiental na propriedade privada e no mercado. Não é atoa que os Beck foram lembrados pelos autores: exploração econômica e preservação ambiental não seriam apenas perfeitamente compatíveis, mas o Ravenna Park a comprovação fática da hipótese. Da mesma forma, reafirma-se, mesmo que tacitamente, a tragédia dos bens comuns: bastou a estatização do parque para o início da destruição ambiental. Transformar cada camada do meio ambiente em propriedade e cada proprietário em um guardião, este é o objetivo da ecologia de mercado.

\subsection{Traços Gerais de uma Ecologia de Livre Mercado}

Na década de 80, na cidade de Bozeman, estado de Montana (EUA), foi criado o PERC (The Property and Environment Research Center), um instituto dedicado exclusivamente aos estudos da ecologia de livre mercado (Free Market environmentalism). Suas publicações se tornaram referência na área, tendo, inclusive, cunhado termo próprio para os pioneiros empresários que se aventuraram no ramo da exploração da preservação ambiental: "enviropreneurs", uma mistura dos termos entrepreneurs e environment.

François Ost (1997; p.155-156), analisando os principais escritos produzidos pelos autores deste centro de pesquisa, assim como de alguns outros, constatou que para o bom desenvolvimento da ecologia de livre mercado são necessários três elementos: "a propriedade privada, o mercado que assegura a sua circulação e o seu desenvolvimento, a responsabilidade que garante a sua perenidade e o seu uso em conformidade com o bem comum".

O sucesso da propriedade privada no combate à degradação ambiental possui diversas explicações. Em primeiro lugar, por ter tomado a frente no combate ao protagonismo estatal na proteção ambiental. Os milhares de exemplos práticos, como o do Ravenna Park, são invocados no intuito de garantir que o Estado, mesmo com o seu principal instrumento - a 
lei - não é capaz de apresentar uma resposta satisfatória ao avanço da degradação ambiental. A apropriação de todos os segmentos da natureza seria, assim, a forma de atrair a iniciativa privada a também se envolver na causa. Nenhuma forma de atrair o interesse seria melhor do que a garantia de lucro.

Em suma:

Diversas razões explicam este sucesso da propriedade: ponto de encontro entre o interesse pessoal e a lógica económica, ela assegura a protecção do recurso em caráter duradouro (o proprietário, seguro do gozo dos frutos de seu capital a curto, médio e longo prazos, tem todo o interesse em administrá-la), induz comportamentos responsáveis (ao invés da gestão pública, a gestão privada faz pagar ao decisor as consequências nefastas das suas escolhas), e contribui mesmo para o desenvolvimento dos bens ambientais (uma vez que estes são permutáveis num mercado, o proprietário será incitado a favorecer o crescimento dos recursos de que dispõe: assim se explica, por exemplo, a criação de quintas de criação de crocodilos ou de borboletas raras e valiosas) (OST: 1997; p. 156).

Como lembra Max Falque (2010; p. 206), a propriedade privada sempre possuiu um papel central no sucesso do desenvolvimento econômico dos países ocidentais: "On commence à redécouvrir que les droits de propriétés sont au cour du développement économique"; e, que a apropriação dos recursos naturais não é apenas possível, como também necessária, já que garantiria a responsabilização daquele que não preservasse seu patrimônio: "En définitive les ressources environnementales peuvent faire l'objet d'appropriation sous une forme directe ou indirecte, ce qui permet de mettre en æuvre le principe de responsabilité du pollueur-payeur" (idem; p.208). Este mesmo autor afirma que a fortificação dos direitos de propriedade individual sobre os recursos naturais promoveriam um benefício triplo: a gestão destes recursos ao seu menor custo, a garantia da liberdade individual e o saneamento do estatismo, que se tornou um calabouçou para a ecologia política (Idem; p. 211).

Henri Lepage (1985; p. 331-332), sob forte influência de Hardin, assevera que as espécies da fauna e da flora que atualmente estão em extinção são aquelas que não se encontram sob o manto da proteção da propriedade, enquanto aquelas que prosperam são justamente as que se encontram submetidas ao direito de propriedade de algum indivíduo. A tendência natural do indivíduo, de sempre buscar o que é melhor para si, aqui, serviria para a 
proteção do ambiente. Sendo assim, contrariamente ao que geralmente se afirma, a solução para a superexploração dos recursos naturais e da destruição da vida selvagem, seria, na realidade, a intensificação de sua apropriação. "Paradoxalement, la propriété est le meilleur allié des amis de la nature" (Idem; p.333).

Não haveria, portanto, contradição entre proteção do meio ambiente e desenvolvimento econômico, mas sim perfeita compatibilidade. A tese também foi defendida por Anderson e Leal, em seu escrito "No longer an axymoron":

When the idea of free market environmentalism was launched in the 1980s, it was considered an oxymoron; today, however, there is hardly an environmentalist who would not concede that markets have a role to play in advancing environmental quality. The general tendency around the world toward freer markets means that populations of the developing world will share in the wealth that markets create and will have the income enabling them to join the ranks of environmentalists. Combining the spark of innovative ideas with the fuel of pragmatic entrepreneurship gives us hope that we can break the regulatory fist of command and control and replace it with a greener invisible hand (ANDERSON; LEAL: 2000; p. 5).

Como se percebe, a noção de um mercado autorregulável no qual estes bens apropriados da natureza poderiam ser comercializados é invocada a todo o momento. Fala-se agora em "mão invisível verde" (ANDERSON; LEAL, 2000, p.5). O exemplo mais curioso levantado por estes estudiosos sobre o papel do mercado provavelmente é o do bisão norteamericano. Como conta Daniel K. Benjamim (2012; p. 18-20), no século XVI as planícies dos Estados Unidos possuíam em torno de 25 a 30 milhões de bisões. Graças à destruição dos habitats naturais e à caça, já no ano de 1850, essa população havia sido reduzida para cerca de 15 milhões, e, entre os anos de 1871 e 1884, foi dizimada, restando apenas algumas centenas de animais, todos em propriedades de terras particulares.

Graças a uma inovação tecnológica de meados de 1870, desenvolvida por indústrias da Inglaterra e da Alemanha, tornou-se fácil a utilização do couro crú do bisão, uma excelente matéria prima para solas de botas e cintos, e, o preço no mercado europeu para o couro do bisão, após removidos os pelos, passou de $\$ 0$ em 1870 para $\$ 2.80$ em 1871, valor que se manteve praticamente estável nos quase quinze anos em que os rebanhos foram dizimados. 
Como expõe Benjamin (idem; p.20), a caça do bisão foi tão intensa que a espécie não se tornou extinta apenas graças a alguns entrepreneurs de visão, que resolveram preservar em suas propriedades alguns "exemplares" da espécie por puro encanto. Com as inovações tecnológicas do século XX, especialmente na área dos transportes, ficou fácil levar à mesa dos americanos a apreciada carne do bisão, surgindo um novo mercado. Os rebanhos então voltaram a crescer e, atualmente, existem mais de 500.000 animais espalhados pelas fazendas dos Estados Unidos, esperando o abate. "Assim como o mercado levou o bisão a ficar perto de ser extinto, também o trouxe de volta da beira do abismo"4 (idem; p.20). O equilíbrio natural e a destruição das espécies seriam, assim, apenas uma questão de visão empreendedora, oferta e procura dentro de um mercado de bens naturais.

O último elemento constituidor das práticas de livre mercado na ecologia é a responsabilidade. Trata-se aqui da defesa da responsabilidade civil em suas definições mais tradicionais: aquele que causar um dano à propriedade de outrem ficará sujeito a indenizá-lo por perdas e danos. Se cada elemento do natural efetivamente se tornasse uma propriedade privada atribuída a um indivíduo, então toda forma de poluição, de destruição do meio ambiente e de espécies da fauna ou da flora nada mais seriam do que danos a propriedades alheias, que deveriam ser indenizados em sua total extensão.

Por um mecanismo relativamente simples, a degradação ambiental se tornaria financeiramente inviável. Todos os empreendedores buscariam reduzir os impactos ambientais de suas atividades porque isso significaria menores custos para a sua produção. Grandes impactos ambientais seriam sinônimo de pouca atratividade em um mercado competitivo. $\mathrm{O}$ raciocínio sequer nos causa estranheza: o Brasil, por exemplo, promulgou por meio do Decreto $n^{\circ} 5.445 / 05$ o Protocolo de Quioto, do qual já era signatário. O dispositivo legal trouxe ao nosso ordenamento jurídico um recurso peculiar: a comercialização dos créditos, ou cotas, de carbono. Trata-se justamente do preconizado: atividades que causarem menor impacto ambiental precisarão adquirir um número menor de "cotas de poluição", tornando-se mais baratas e ganhando uma efetiva vantagem competitiva. 
Neste ponto, entretanto, a ecologia de mercado esbarrou nos Tribunais. Conta Ost (1997; p.159) que durante o século XIX os tribunais foram lentamente abandonando a concepção clássica da responsabilidade graças à construção da "teoria da licitude de utilização da propriedade". Se a utilização é lícita, ainda que ela cause danos a terceiros, estes não precisarão ser indenizados. O art. 927 do Código Civil brasileiro é exemplo notável desta construção teórica: “Aquele que, por ato ilícito (arts. 186 e 187), causar dano a outrem, fica obrigado a repará-lo". Não basta mais causar um dano a outrem. Para ser indenizável o dano deve ser ilícito. E quem decidirá sobre a ilicitude do dano é o próprio Poder Judiciário.

Durante o século XX o processo foi acentuado. Graças à inabalável fé no avanço industrial, as indenizações passaram a serem vistas como impecílios ao progresso. "A partir de agora, é a administração quem irá gerir os riscos ambientais, fixando as condições de concessão das licenças de poluir, e isto a respeito das oportunidades económicas e sociais" (OST: 1997; p.160). O caso paradigma desta doutrina, nos Estados Unidos, chamou-se caso Ryan. A New York Central Railroad, empresa dedicada à construção de ferrovias nos Estados Unidos, foi dispensada de indenizar os habitantes da cidade de Siracusa que tiveram suas casas incendiadas pelas fagulhas dos comboios. A dimensão do dano foi justamente a justificativa do Tribunal: o prejuízo à sociedade seria maior com a falência da empresa do que com a não indenização das vítimas dos incêndios (idem; p. 159-160).

Apesar de todas as distorções, o triunfo prático das proposições levou a ecologia de livre mercado a um papel de grande destaque nas discussões da década de 90 . A tradição jurídica da maioria dos países ocidentais sempre deu grande ênfase à defesa dos direitos dos proprietários individuais, sendo assim, não surpreende a rapidez com que os sistemas jurídicos reconheceram as práticas destes ecologistas. "Nada melhor do que uma escritura em um Tribunal" (ANDERSON; LEAL: 2000; p. 3).

Como argumenta Anderson e Leal (idem; p. 3), quando o direito de propriedade é definido e fortalecido, a proteção do meio ambiente fica segura, graças à força da Constituição e dos precedentes legais. Diversas entidades que carregam a bandeira da causa ecológica passaram a adotar práticas de mercado, não por concordarem com suas posições, mas por serem as únicas que efetivamente trazem resultados rápidos e duradouros ${ }^{5}$. A Natural 
Conservancy, por exemplo, adotou nos Estados Unidos uma estratégia de compra maciça de terras a serem preservadas, chamando a tática de private lands conservation. Atualmente, é proprietária, naquele país, de mais de 6 milhões de hectares de terra ${ }^{6}$, contando, inclusive, com uma política de identificação de áreas prioritárias de aquisição, em geral, as que possuem espécies de fauna ou flora em risco de extinção ou em maior risco de deflorestamento.

Basta ler os volumes da revista editada pelo PERC, a PERC Reports ${ }^{7}$, para perceber que as discussões se concentram ao redor dos modelos práticos de sucesso de empreendimentos. Apenas como exemplo, toma-se o primeiro volume de 2012 da PERC Reports. Temos um caso de ranchos no Texas, nos quais eram criados animais selvagens africanos ameaçados de extinção voltados para o mercado do turismo de caça (ANDERSON: 2012; p.4). A prática salvou diversas espécies que posteriormente acabaram extintas na África, seu habitat natural, como é o caso do Órix-cimitarra.

$\mathrm{Na}$ mesma edição temos ainda uma grande reportagem sobre como canetas feitas de madeira estariam ajudando a preservar pinheiros centenários (REGAN: 2012; p.12-17), ao final, inclusive, vê-se um anúncio comercial para a aquisição das tais canetas; outra sobre o comércio e restauração de corais no estado da Flórida, voltados para o turismo aquático (WATSON: 2012; p.20-25); e, finalmente, um artigo que trata da delicada questão dos gambás, que, levados por imigrantes ingleses à Austrália, meio ambiente no qual não possuíam predadores, logo se tornaram uma praga, destruindo plantações, espécies nativas da flora e o habitat de outras espécies da fauna local (PLATTS: 2012; p.37). Neste artigo especialmente interessante, a autora defende os empreendedores que, explorando o comércio de peles, ajudam a diminuir sua população, enumerando nada menos que sete formas de se utilizar a pele de gambá. Conta ainda, com algum entusiamo, a criação de uma nova máquina que serviria para abater os gambás de uma forma humana: utilizando um pistão movido a dióxido de carbono para esmagar os crânios.

Não se pode negar que gerar lucro e desenvolvimento econômico a partir da proteção do meio ambiente é uma ideia tentadora, todavia, essa corrente de pensamento passou longe de ficar imune às críticas. Como afirma François Ost (1997; p. 161-163), logo à 
primeira vista se percebe que a corrente é absolutamente reducionista. Não se pode afirmar que a sociedade se limita a ser uma série de proprietários individuais e que a vida social é apenas uma constante troca de mercadorias. A própria visão de meio ambiente é limitada: os ecossistemas são vistos apenas como o somatório de diversos objetos estáticos, esperando apropriação:

Tudo se passa, igualmente, como se o ambiente - ou seja, a problemática ecológica enquanto tal, os ecossistemas, a biosfera - se reduzisse a uma soma de parcelas vizinhas e isoladas, cujas trocas bioquímicas, positivas e negativas, fossem sempre susceptíveis de avaliação monetária, e, logo, de compensação. Ora como ignorar, hoje, que a realidade ecológica é simultaneamente global e complexa e, logo, decididamente estranha à divisão puramente contabilizável e à avaliação exclusivamente monetária? Sem dúvida que, nestes vastos conjuntos inapropriáveis e não contabilizáveis, podem ser isoladas zonas e retirados recursos que encontram preço num mercado: mas os conjuntos enquanto tais (património genético, ciclos bioquímicos, clima, etc) escapam a este reducionismo (OST: 1997; p.161-162).

Como atribuir valor monetário a danos ambientais que se prolongam por décadas até que suas consequências sejam palpáveis, como é o caso daqueles causados pela emissão de gases de efeito estufa ou por acúmulo de agrotóxicos em solos e no leito de rios? Qual será a parcela de "culpa", e, portanto, de indenização, atribuível a cada um dos agressores? Ademais, é impossível, hoje, afastar o caráter dinâmico e global dos danos ambientais. Como definir e mercantilizar as consequências da destruição de uma floresta para os demais ecossistemas de um mesmo continente? E para o clima de todo o mundo? E ainda, quem será responsabilizado pela interação catastrófica entre poluentes? Não é raro percebermos duas empresas despejando resíduos em um rio, que, isoladamente, possuem um baixo potencial de agressividade, mas que, combinados, são devastadores.

A ecologia, uma ciência que estuda o global, o dinâmico e o complexo e não o local, simples e estático, não pode aceitar as premissas da ecologia de livre mercado. Não faz sentido, cientificamente, admitir a divisão, estratificação e mercantilização de elementos isolados da natureza. É impossível aferir, de imediato, os danos e as consequências causadas por determinada espécie de poluição. Sendo assim, longe de gerar a responsabilização do poluidor, a ideia, na realidade, gera a impunidade, já que envolve as discussões sobre dano e indenização em um gigantesco emaranhado de causas e efeitos, dificilmente aferíveis entre si, 


\section{A AQUISIÇÃO DE TERRAS BRASILEIRAS POR ESTRANGEIROS [...]}

perdidos na vasta gama de interações.

Ademais, é discutível a própria veracidade do mito fundador da ecologia de livre mercado, a tragédia dos bens comuns. Como explicar, então, que durante séculos as sociedades civis, em seu próprio seio, regulamentaram a utilização dos recursos naturais, em uma situação de relativo equilíbrio? Como demonstra Ost, as intervenções estatais só passaram a ocorrer graças aos crescentes abusos do direito de propriedade e das inconsequências dos mercados:

Sem dúvida, depois de alguns decénios, o intervencionismo estatal veio sobrepor-se à exploração privada dos recursos ambientais, mas em que medida seria isso suficiente para fazer esquecer que, desde 1804 pelo menos, a natureza não deixou de ser um objecto de apropriação e de transacção privadas? E, por muito inábeis e por vezes venais que fossem as intervenções do poder público, não tinham elas por primeira função corrigir os abusos da propriedade e as perturbações do mercado? É claro verificar, que é a própria alternativa a que Hardin nos quer constranger, que é falsa e que é preciso rejeitar: não será o público (diabolizado), ou o privado (angelizado) - e isso pela razão bem simples de que, nem um nem outro existem no estado puro na realidade (OST: 1997; p. 163).

Como se percebe, longe de se mostrar como uma solução viável à crise ambiental, a ecologia de mercado parece mais uma tentativa da própria forma contemporânea de produção de explorar a crescente consciência ambiental que vem sendo incutida aos consumidores deste mercado. Como se pode preservar a natureza quando a própria valorização dos produtos no mercado necessariamente exige sua raridade? A ecologia de livre mercado torna-se assim apenas uma forma de aproveitar a repulsa à degradação ambiental, porém, intrinsecamente ligada a ela. Como pode ser este um efetivo meio de proteger a natureza, se seu mecanismo exige a existência de destruição?

Até mesmo quando as práticas destes ecologistas não são voltadas precipuamente à comercialização no mercado, como é o caso, por exemplo, das aquisições de largas quantias de terras por instituições protetoras, como o Natural Conservacy, as práticas são claramente insuficientes, já que são inaplicáveis em larga escala. Adquire-se apenas extratos da natureza que possuem evidente benefício ecológico: belas paisagens, florestas onde existem espécies raras e em extinção. Mas, quem irá cuidar daquilo que não é belo? Daquilo que é 
absolutamente necessário ao frágil equilíbrio ecológico, apesar de não possui qualquer valor comercial? A fragilidade da ecologia de mercado fica evidente quando confrontada com tais questões.

\section{Instituto Jurídico da Aquisição de Terras Brasileiras por Estrangeiros}

2.1 Histórico do Instituto no Ordenamento Jurídico Brasileiro

O primeiro diploma normativo a tratar da questão da aquisição de terras por estrangeiros no Brasil foi a Lei de Terras (Lei no 601 de 18 de setembro de 1850). Como se sabe, o Estado brasileiro possuía um projeto de colonização à época que consistia na venda de terras devolutas nacionais para financiar a vinda de colonos europeus para o país. De acordo com o artigo 18 do diploma, o governo autorizou a vinda de colonos livres, anualmente, às custas do Tesouro, para serem empregados em estabelecimentos agrícolas ou em trabalhos apontados pela Administração Pública. O artigo 19, ainda, estabeleceu que os valores oriundos da venda das terras devolutas deveria ser aplicado exclusivamente na medição de terras devolutas e na "importação" de colonos livres.

Sendo assim, não é de se estranhar que era permitida a aquisição de terras brasileiras por estrangeiros, ainda que estes não estivessem definitivamente domiciliados no país. Antes mesmo de chegar ao território brasileiro, o estrangeiro já poderia adquirir terras. De acordo com o art. 17 da Lei de Terras, todo estrangeiro que comprasse terras brasileiras e nelas se estabelecessem pelo prazo de dois anos, poderiam, inclusive requerer a naturalização.

Logo em seguida, no ano de 1854, foi promulgado o Decreto do governo imperial $\mathrm{n}^{\circ} 1.318$, que determinava a criação de colônias militares dentro de 10 léguas das fronteiras com os países estrangeiros. Nessa faixa de 10 léguas, apenas brasileiros poderiam adquirir terras, demonstrando, pela primeira vez, associação nítida entre política fundiária e segurança nacional.

Em 1889 veio a Proclamação da República e em 1891 sua Constituição, que, em seu art. 64, determinava que pertenciam aos estados as minas e terras devolutas situadas em seus respectivos territórios, pertencendo à União apenas aquela porção do território 
indispensável para a defesa das fronteiras, fortificações, contruções militares e estradas de ferro.

Como se percebe, o tema da aquisição de terras por estrangeiros continuava carecendo de maiores contornos legais, possuindo dispositivos voltados apenas à segurança nacional. A Constituição de 1934, eivada de um sentimento nacionalista artificialmente estimulado pelo governo Vargas, falava em preferência ao trabalhador nacional nas políticas fundiárias e de colonização. Não se tratava necessariamente de vedação à participação de estrangeiros, mas de mera preferência ao nacional, o que não foi alterado com a Constituição de 1937. Como dizia o caput do art. 121 e seu $\$ 4^{\circ}$, a ordem jurídica visaria a proteção social do trabalhador, tanto nas cidades quanto nos campos, e buscaria fixar o homem no campo, assegurando ao trabalhador nacional preferência na colonização e no aproveitamento das terras públicas. A Constituição de 1946 pouco mudou a política estabelecida em 1934, mantendo, por meio de seu art. 156, a política de preferência por trabalhadores nacionais nos planos de colonização e aproveitamento de terras públicas.

O Estatuto da Terra (Lei 4.504), publicado em 1964, não tratou diretamente da aquisição de terras por estrangeiros. Sua única inovação explícita foi permitir que estrangeiros "radicados" no país pudessem participar dos programas de reforma agrária e colonização. Atribuindo ao Instituto Brasileiro de Reforma Agráfia algumas das atribuições da antiga Superintendência de Política Agrária, em seu art. 115, inciso I e alínea "a", a lei determinou que estrangeiros radicados no país também poderiam participar dos programas de colonização e fixação do homem à terra.

Após a Constituição de 1967 não estabelecer grandes novidades às políticas já instituídas, a Constituição de 1969, que formalmente foi apenas a Emenda Constitucional $\mathrm{n}^{\circ} 1$ à Constituição de 1967, demonstrou um início de preocupação em criar regras distintas de aquisição de propriedade rural para brasileiros e para estrangeiros. De acordo com o $\S 34$ do art. 153, "A lei disporá sobre a aquisição da propriedade rural por brasileiro e estrangeiro residente no país, [...] estabelecendo condições, restrições, limitações e demais exigências [...]". Nota-se a diferenciação entre aquisição da propriedade rural por brasileiros e por 
estrangeiros.

Apenas com a outorga do Ato Complementar $n^{\circ} 45$, ainda em 1969, que a proibição à aquisição de terras por estrangeiro não residente no Brasil torna-se expressa logo em seu art. $1^{\text {o: }}$ “A aquisição de propriedade rural no território nacional somente poderá ser feita por brasileiro ou por estrangeiro residente no país."

Como se percebe, o regime militar ditatorial demonstrava clara propensão em limitar ao máximo a aquisição de terras brasileiras por estrangeiros não residentes no país. Baseado no Ato Complementar $\mathrm{n}^{\circ} 45$ foram outorgados, ainda no ano de 1969, os Decretos-lei de $n^{\circ} 494$ e 924. Em relação ao primeiro, destacam-se as exigências de autorização do Ministério da Agricultura, intermediado pela IBRA (Instituto Brasileiro de Reforma Agrária), para que estrangeiros pudessem adquirir terras nacionais (arts. $1^{\circ}, \S^{\circ}$ e art. $6^{\circ}, \S 1^{\circ}$ ); a fixação de limites, proporcionais ao tamanho do município para a apropriação de terras por estrangeiros $\left(\operatorname{art} .8^{\circ}\right)$; e, especialmente, que pessoas jurídicas estrangeiras só poderiam adquirir terras se estivessem autorizadas a funcionar no país, e que só poderiam adquirir terras para a utilização nos objetivos descritos em seu estatuto social (art. $6^{\circ}$ ). O segundo decreto, por outro lado, determinava que a aquisição de terras para empreendimentos industriais não se sujeitavam aos limites impostos pelo Decreto-lei no 494.

De toda forma, em outubro de 1971 foi publicada a Lei $\mathrm{n}^{\circ} 5.709$, que revogou tanto o Decreto-lei n 494 quanto o de n ${ }^{\circ}$ 924, tornando-se, até hoje, o principal diploma legal a tratar da matéria, apesar de posteriormente ter sofrido algumas modificações. As restrições previstas são de diversas naturezas:

a) Quanto ao tamanho da propriedade (art. $\left.3^{\circ}\right)$ :

A aquisição de imóvel rural por pessoa física estrangeira não poderá exceder a 50 (cinquienta) módulos de exploração indefinida, em área contínua ou descontínua.

$\S 1^{\circ}$ - Quando se tratar de imóvel com área não superior a 3 (três) módulos, a aquisição será livre, independendo de qualquer autorização ou licença, ressalvadas as exigências gerais determinadas em lei.

$\S 2^{\circ}-$ O Poder Executivo baixará normas para a aquisição de área 
compreendida entre 3 (três) e 50 (cinqüenta) módulos de exploração indefinida.

b) Quanto ao percentual em loteamentos rurais efetuados por empresas particulares de colonização $\left(\operatorname{art} .4^{\circ}\right)$ :

Nos loteamentos rurais efetuados por empresas particulares de colonização, a aquisição e ocupação de, no mínimo, $30 \%$ (trinta por cento) da área total serão feitas obrigatoriamente por brasileiros.

b) Necessidade de vinculação dos imóveis rurais adquiridos aos objetivos estatutários das pessoas jurídicas estrangeiras ou brasileiras a elas equiparadas $\left(\operatorname{art} .5^{\circ}\right.$ ):

As pessoas jurídicas estrangeiras referidas no art. $1^{\circ}$ desta Lei só poderão adquirir imóveis rurais destinados à implantação de projetos agrícolas, pecuários, industriais, ou de colonização, vinculados aos seus objetivos estatutários.

c) Localização $\left(\operatorname{art} .7^{\circ}\right)$ :

A aquisição de imóvel situado em área considerada indispensável à segurança nacional por pessoa estrangeira, física ou jurídica, depende do assentimento prévio da Secretaria-Geral do Conselho de Segurança Nacional.

d) Forma (art. $8^{\circ}, 9^{\circ}$ e 10$)$ :

Art. $8^{\circ}$ - Na aquisição de imóvel rural por pessoa estrangeira, física ou jurídica, é da essência do ato a escritura pública.

Art. $9^{\circ}$ - Da escritura relativa à aquisição de área rural por pessoas físicas estrangeiras constará, obrigatoriamente:

I - menção do documento de identidade do adquirente;

II - prova de residência no território nacional; e

III - quando for o caso, autorização do órgão competente ou assentimento prévio da Secretaria-Geral do Conselho de Segurança Nacional.

Parágrafo único. Tratando-se de pessoa jurídica estrangeira, constará da escritura a transcrição do ato que concedeu autorização para a aquisição da área rural, bem como dos documentos comprobatórios de sua constituição e de licença para seu funcionamento no Brasil.

Art. 10 - Os Cartórios de Registro de Imóveis manterão cadastro especial, em livro auxiliar, das aquisições de terras rurais por pessoas estrangeiras, físicas e jurídicas, no qual deverá constar: 
I - menção do documento de identidade das partes contratantes ou dos respectivos atos de constituição, se pessoas jurídicas;

II - memorial descritivo do imóvel, com área, características, limites e confrontações; e

III - transcrição da autorização do órgão competente, quando for o caso.

e) Controle de aquisições (art. 11):

Trimestralmente, os Cartórios de Registros de Imóveis remeterão, sob pena de perda do cargo, à Corregedoria da Justiça dos Estados a que estiverem subordinados e ao Ministério da Agricultura, relação das aquisições de áreas rurais por pessoas estrangeiras, da qual constem os dados enumerados no artigo anterior.

Parágrafo único. Quando se tratar de imóvel situado em área indispensável à segurança nacional, a relação mencionada neste artigo deverá ser remetida também à Secretaria-Geral do Conselho de Segurança Nacional.

e) Extensão total de terras em um mesmo município (art. 12):

A soma das áreas rurais pertencentes a pessoas estrangeiras, físicas ou jurídicas, não poderá ultrapassar a um quarto da superfície dos Municípios onde se situem, comprovada por certidão do Registro de Imóveis, com base no livro auxiliar de que trata $\mathrm{o}$ art. 10 .

$\S 1^{\circ}$ - As pessoas da mesma nacionalidade não poderão ser proprietárias, em cada Município, de mais de $40 \%$ (quarenta por cento) do limite fixado neste artigo.

$\S 2^{\circ}$ - Ficam excluídas das restrições deste artigo as aquisições de áreas rurais:

I - inferiores a 3 (três) módulos;

II - que tiverem sido objeto de compra e venda, de promessa de compra e venda, de cessão ou de promessa de cessão, mediante escritura pública ou instrumento particular devidamente protocolado no Registro competente, e que tiverem sido cadastradas no INCRA em nome do promitente comprador, antes de 10 de março de 1969;

III - quando o adquirente tiver filho brasileiro ou for casado com pessoa brasileira sob o regime de comunhão de bens.

f) Doação por entes públicos (art. 14):

Salvo nos casos previstos em legislação de núcleos coloniais, onde se estabeleçam em lotes rurais, como agricultores, estrangeiros imigrantes, é vedada, a qualquer título, a doação de terras da União ou dos Estados a pessoas estrangeiras, físicas ou jurídicas.

Como se percebe, o regime jurídico de aquisição de terras brasileiras por estrangeiros determinada pela Lei $\mathrm{n}^{\circ} 5.709 / 71$ é bastante restritivo. Apesar disso, a lei continuou em pleno vigor até promulgação da Constituição de 1988, quando a recepção de 


\section{A AQUISIÇÃO DE TERRAS BRASILEIRAS POR ESTRANGEIROS [...]}

alguns de seus dispositivos passou a ser questionada.

2.2 A Constituição de 1988 e a Validade da Lei 5.709/71

A Constituição da República de 1988 não trouxe grandes inovações ao tema, limitando-se a dizer, em seu art. 190, que a aquisição e o arrendamento de terras por estrangeiros deveriam ser regulamentados por lei, e, inclusive, em alguns casos, sujeitos à autorização prévia do Congresso Nacional. O dispositivo infraconstitucional que regulamentava a prática continuou sendo a Lei 5.709/71. Apesar da série de restrições, o ponto controvertido do diploma foi seu âmbito de aplicação:

Art. $1^{\circ}$ - O estrangeiro residente no País e a pessoa jurídica estrangeira autorizada a funcionar no Brasil só poderão adquirir imóvel rural na forma prevista nesta Lei.

$\S 1^{\circ}$ - Fica, todavia, sujeita ao regime estabelecido por esta Lei a pessoa jurídica brasileira da qual participem, a qualquer título, pessoas estrangeiras físicas ou jurídicas que tenham a maioria do seu capital social e residam ou tenham sede no Exterior.

Não havia qualquer dúvida quanto à aplicação da lei às pessoas físicas e jurídicas estrangeiras, todavia, o $\$ 1^{\circ}$ era problemático, já que equiparava à estrangeira a pessoa jurídica brasileira cujo capital social fosse, em sua maioria, controlado por estrangeiros. A controvérsia se deu no momento da entrada em vigor da nova Constituição, que previa, no texto do art. 171 (antes deste ser revogado pela EC $n^{\circ}$ 6/95), distinção entre empresa brasileira e empresa brasileira de capital nacional.

De acordo com a Constituição (art. 171), para uma empresa ser considerada brasileira, bastava que ela fosse constituída de acordo com a legislação brasileira e que possuísse sede e administração em território nacional. Já a empresa brasileira de capital nacional, além destes requisitos, deveria estar permanentemente sob o controle de pessoas físicas domiciliadas ou pessoas jurídicas sediadas no Brasil. O motivo desta diferenciação seria o estímulo à criação e ao crescimento das empresas nacionais de capital nacional, com a elaboração de políticas públicas exclusivas a estas. 
Entretanto, começou-se a questionar a validade do $\S 1^{\circ}$ da Lei $5.709 / 71$. Poderia um ato normativo infraconstitucional tratar como empresa estrangeira aquelas que a Constituição expressamente taxou como nacionais, como era o caso das empresas brasileiras cuja maioria do capital social pertencia a estrangeiros? Caberia à lei fazer uma diferenciação que pretensamente não havia sido feita pela própria Constituição?

A Advocacia Geral da União (AGU) foi provocada a se manifestar sobre o tema, editando o parecer GQ-22 em 1994. Segundo o parecer, não seria possível admitir as restrições da Lei 5.709/71 às empresas constituídas sob as leis brasileiras que possuíssem sede e administração em território nacional. O principal argumento seria que a Constituição tratou essas empresas como nacionais, não cabendo, portanto, a um dispositivo infraconstitucional tratá-las como estrangeiras. Dessa forma, para a AGU, o $§ 1^{\circ}$ do art. $1^{\circ}$ da Lei 5.709/71 não havia sido recepcionado pela atual Constituição.

Apesar de não se tratar de um pronunciamento jurisdicional a respeito da matéria, os pareceres da AGU vinculam o órgão da Administração que o solicitou, como prescrito no art. $40, \S 2^{\circ}$ da Lei complementar $n^{\circ} 73$. Neste caso, o posicionamento vinculou o Ministério da Agricultura, justamente o órgão responsável pela fiscalização da aquisição de terras por estrangeiros em território nacional, gerando profundas consequências práticas. A partir deste momento, bastava criar uma pessoa jurídica sob as leis brasileiras, sediada e administrada no Brasil, controlada por estrangeiros, para burlar as restrições da Lei 5.709/71.

Em 1995 foi publicada a EC n6, que revogou o art. 171 da Constituição da República, eliminando do texto constitucional a definição de empresa nacional, e, em consequência, a diferenciação que existia entre empresa nacional e empresa nacional de capital nacional. Novamente a AGU foi provocada a se manifestar sobre o assunto, exarando o parecer GQ-181, que foi aprovado pelo Presidente da República e publicado no Diário Oficial da União, adquirindo, portanto, força vinculativa sobre toda a Administração Pública, graças ao art. $40, \S 1^{\circ}$ da Lei Complementar $n^{\circ} 73$.

No segundo parecer, a AGU defendeu que o texto originário da Constituição não havia recepcionado $o \S 1^{\circ}$ do art. $1^{\circ}$ da Lei 5.709/71, graças à incompatibilidade com o art. 171 
da Carta Magna. Desta forma, mesmo que o art. 171 tenha sido revogado pela $E C \mathrm{n}^{\circ}$ 6/95, o $\S 1^{\circ}$ do art. $1^{\circ}$ da Lei $5.709 / 71$ continuará revogado. Em suma, não existiria repristinação no ordenamento constitucional brasileiro. Um dispositivo revogado não volta a vigorar quando sua norma revogadora é, por sua vez, revogada. Desta forma, na prática, continuou liberada a aquisição de terras brasileiras por estrangeiros, uma vez que era muito fácil burlar as restrições impostas pela Lei 5.709/71.

O relaxamento das restrições, entretanto, tornou-se motivo de preocupação. Como descrito no parecer da AGU CGU/AGU No 01/2008 - RVJ (BRASIL: 2010; p.3-4), foi realizada uma reunião do Ministério da Casa Civil da Presidência da República para tratar justamente do tema da aquisição de terras por estrangeiros e o até então vigente parecer da AGU GQ-181:

7. Tal situação revestia-se, então, em junho de 2007, e reveste-se, ainda, de caráter estratégico, pois, a ausência de controle dessas aquisições gera, entre outros, os seguintes efeitos:

a) expansão da fronteira agrícola com o avanço do cultivo em áreas de proteção ambiental e em unidades de conservação;

b) valorização desarrazoada do preço da terra e incidência da especulação imobiliária gerando aumento do custo do processo desapropriação voltada para a reforma agrária, bem como a redução do estoque de terras disponíveis para esse fim;

c) crescimento da venda ilegal de terras públicas;

d) utilização de recursos oriundos da lavagem de dinheiro, do tráfico de drogas e da prostituição na aquisição dessas terras;

e) aumento da grilagem de terras;

f) proliferação de "laranjas" na aquisição dessas terras;

g) incremento dos números referentes à biopirataria na Região Amazônica;

h) ampliação, sem a devida regulação, da produção de etanol e biodiesel;

i) aquisição de terras em faixa de fronteira pondo em risco a segurança nacional.

8. Passados quatorze anos, o novo contexto econômico mundial, rapidamente descrito anteriormente, impunha um reposicionamento do Governo Federal sobre o tema, valendo-se dos instrumentos disponíveis, dentre os quais a eventual revisão do Parecer AGU/GQ-181 e do Parecer AGU/GQ-22 (BRASIL: 2010; p.4)

O Parecer CGU/AGU n ${ }^{\circ}$ 01/2008-RVJ, aprovado pelo parecer LA01-10, é o produto da nova provocação feita à AGU para se manifestar sobre o tema. O resultado da consulta, entretanto, foi surpreendente. Em primeiro lugar, afirmou o advogado da União, contrariamente ao que havia sido defendido no parecer GQ-22/94, que nunca houve 
incompatibilidade entre o art. 171, enquanto estava em vigor, e o $\S 1^{\circ}$ do art. $1^{\circ}$ da Lei 5.709/71. Segundo o novo parecer, o art. 171 da Constituição tratou de estabelecer restrições genéricas às empresas brasileiras em relação às de capital nacional, e, era exatamente isso que a Lei 5.709/71 fazia, aplicando as restrições da aquisição de terras impostas aos estrangeiros às empresas brasileiras que não possuíam capital nacional. A norma infraconstitucional, portanto, não estava criando uma discriminação que a Lei Maior não havia criado, mas sim, colocando efetivamente em prática a finalidade da distinção existente.

Estando em vigor o $\S 1^{\circ}$ do art. $1^{\circ}$ da Lei 5.709/71, nenhuma consequência trouxe a revogação do art. 171 da Constituição pela EC nº6/95. À época do parecer GQ-181, a AGU argumentou que o fim da distinção entre empresa brasileira e empresa brasileira de capital nacional também trazia a fim a inconstitucionalidade do $\S 1^{\circ}$ do art. $1^{\circ}$ da Lei 5.709/71, todavia, este dispotivo não poderia voltar a vigor, uma vez que o ordenamento jurídico brasileiro não admite a repristinação. Ora, se o dispositivo foi perfeitamente recepcionado pela Constituição, como agora entende a AGU, e, na realidade, nunca fora revogado, não há qualquer motivo para se discutir repristinação. Atualmente, portanto, o $\S 1^{\circ}$ do art. $1^{\mathrm{o}}$ da Lei 5.709/71 está em vigor. Neste sentido, citam-se as conclusões finais do parecer CGU/AGU n ${ }^{\circ}$ 01/2008-RVJ:

Por todo o exposto, divirjo da NOTA No AGU/GM 24/2007, e sustento:

a) que o $\S 1^{\circ}$ do art. $1^{\circ}$ da Lei $n^{\circ} 5.709$, de 1971 , foi recepcionado pela Constituição Federal de 1988, seja em sua redação originária, seja após a promulgação da Emenda Constitucional $\mathrm{n}^{\circ}$ 6, de 1995, por força do que dispunha o art. $171, \S 1^{\circ}$, II e do que dispõem o art. $1^{\circ}$, I; art. $3^{\circ}$, II; art. $4^{\circ}$, I; art. $5^{\circ}$, caput; art. 170, I e IX; art. 172 e art.190;

b) para que a equiparação de pessoa jurídica brasileira com pessoa jurídica estrangeira prevista no dispositivo legal citado no item anterior ocorra, a fim de que sejam estabelecidos limites e restrições à aquisição e ao arrendamento de imóveis rurais é necessário que:

i. o estrangeiro, pessoa física, seja não-residente ou a pessoa jurídica não possua sede no país;

ii. o estrangeiro, pessoa física ou jurídica, descrito no item anterior, participe, a qualquer título, de pessoa jurídica brasileira; e

iii. essa participação assegure a seus detentores o poder de conduzir as deliberações da assembléia geral, de eleger a maioria dos administradores da companhia e de dirigir as atividades sociais e orientar o funcionamento dos órgãos da companhia.

c) que em face do entendimento contido nos itens anteriores, o Parecer $n^{\circ}$ GQ-181, de 1998, e o Parecer GQ-22, de 1994, merecem a revogação, devendo, para tanto, ser o presente Parecer submetido à aprovação do Exm ${ }^{\circ}$ 
Sr. Presidente da República, após a aprovação de V. Exa ${ }^{\mathrm{a}}$, e, posteriormente, publicado no Diário Oficial da União para que, por força do art. 40 da Lei Complementar $\mathrm{n}^{\mathbf{0}} 73$, de 1993, produza efeitos vinculantes para toda a administração pública federal (BRASIL: 2010; p. 36).

É necessário destacar que o parecer CGU/AGU no 01/2008-RVJ foi aprovado pelo Presidente da República e publicado no Diário Oficial da União, passando, por força do art. 40 da Lei complementar $n^{\circ} 73$, a vincular todos os órgãos da Administração Pública. O INCRA e o Ministério da Agricultura voltaram a se tornar responsáveis pela fiscalização da legalidade das aquisições.

A volta das restrições à aquisição de terras por estrangeiros, entretanto, não vieram imunes às críticas. O jornal Estado de São Paulo (FERREIRA: 2012; p.2), em recente reportagem, demonstrou como a Frente Parlamentar da Agropecuária está insatisfeita com as restrições às aquisições. Para parlamentares como Homero Pereira (PDT), o agronegócio brasileiro vem perdendo um grande volume de investimentos graças a essas limitações, citando nominalmente como exemplo o setor sucroalcooleiro. Não causa estranheza, portanto, que esse mesmo parlamentar tenha elaborado um substitutivo ao Projeto de Lei (PL) $\mathrm{n}^{\mathrm{o}}$ 2.289/07, de autoria do Deputado Beto Faro (PT-PA), ainda em trâmite no Congresso Nacional, que visa justamente criar um novo diploma jurídico para regulamentar a aquisição de terras brasileiras por estrangeiros, revogando, assim, a Lei 5.709/71.

Caso aprovado o texto do substitutivo, ficariam restritas as aquisições de terras brasileiras por ONGs estrangeiras ou brasileiras cuja maioria de seu orçamento seja proveniente de fontes estrangeiras. Também ficariam proibidos de adquirir terras brasileiras os fundos soberanos de outros países. As pessoas jurídicas brasileiras com capital social preponderantemente nas mãos de estrangeiros, todavia, poderiam adquirir livremente terras brasileiras.

Observando a rapidez com que tramita o PL $\mathrm{n}^{\mathrm{o}} 2.289 / 07^{8}$, e os inúmeros pronunciamentos da bancada governista no Congresso Nacional, confome apurou Oliveira (2010; p.101-103), pode-se afirmar, com alguma segurança, que o risco de uma maleabilização das restrições constantes na Lei 5.709/71, ou até a completa revogação do 
dispotivo, são bastante reais. Sendo assim, quais seriam as consequências da abertura da fronteira brasileira à aquisição de terras pelos ecologistas de livre mercado? Seria esse, realmente, o futuro da ecologia mundial?

\section{Críticas à Possibilidade de Aquisição de Terras Brasileiras por Estrangeiros para as Práticas da Ecologia de Livre Mercado}

Como já foi abordado, o grande triunfo da ecologia de livre mercado, que a levou a conquistar algum destaque na década de 90, foi a sua capacidade de encontrar soluções rápidas e duradouras ainda que apenas para alguns problemas pontuais. Como Anderson (2012; p.4) disse, os enviropreneurs são verdadeiros pioneiros dos "negócios verdes", buscando soluções pragmáticas nos locais onde onde os ambientalistas tradicionais só conseguem visualizar problemas. Onde a ecologia tradicional vê destruição, a ecologia de mercado vê oportunidade. E a maleabilização das restrições à aquisição de terras por estrangeiros é uma grande oportunidade.

Nos Estados Unidos a prática de compra de terras para a formação de reservas florestais já é bastante utilizada e vem recebendo críticas positivas. O exemplo da Natural Conservancy é bastante elucidativo. Trata-se de uma organização ambiental que atua em mais de 30 países no combate à degradação ambiental. As práticas são visivelmente de ecologia de mercado. Por exemplo, nos Estados Unidos, a organização adquiriu, por meio de compra, mais de 6 milhões de hectares de terras ${ }^{9}$, para a preservação de espécies da fauna e da flora em risco de destruição.

A instituição também atua no Brasil, e, como podemos observar em seu sítio eletrônico $^{10}$, as práticas não são tão diferentes. Apesar de não comprarem terras fora do território dos Estados Unidos, a instituição fomenta a criação de Unidades de Convervação em solo brasileiro (UCs), e a criação de Reservas Particulares do Patrimônio Natural (RPPNs). Transformar terras privadas em reservas ecológicas para a exploração econômica de atividades como o turismo é uma prática clássica da ecologia de mercado. Outra iniciativa fomentada pelo instituto é a expansão do chamado "ICMS ecológico"11. Trata-se de um mecanismo criado para que os municípios que levarem a preservação das florestas nativas a 
sério sejam beneficiados pelo repasse de um porcentual do ICMS tradicional, aumentando a arrecadação do município. Aliás, no sítio eletrônico da iniciativa, a atual luta da instituição é para que Reservas Particulares de Patrimônio Natural também possam entrar na repartição dos valores.

Um exemplo da prática é o caso do município de São Pedro do Ivaí, que firmou um convênio com a Fazenda Barbacena, uma Reserva Particular de Patrimônio Natural. Como se vê na Lei municipal no 1.211/2007, a Câmara Municipal aprovou que 60\% de todos os repasses de ICMS ecológico recebidos pelo município ficariam com a fazenda. Entre 2005 e 2010, os valores repassados à Fazenda Barbacena chegaram a $\mathrm{R} \$ 820.000,00^{12}$. Um belo exemplo da lógica de mercado incentivando a preservação ambiental no Brasil.

Outro exemplo vem do município de Varre-Sai, no estado do Rio de Janeiro. A lei municipal $n^{\circ} 572 / 2010$ criou um sistema municipal de conservação da biodiversidade do município, autorizando o repasse de valores recebidos do ICMS ecológico para uma associação civil sem fins lucrativos que, por sua vez, se incumbiria de distribuir os valores entre todos os proprietários de RPPNs. Vale destacar que o estado do Rio de Janeiro criou a previsão de pagamento de ICMS ecológico, ou verde, pela Lei estadual n ${ }^{\circ}$ 5.100/07.

Outra iniciativa de proteção ambiental que foi apoiada pela instituição foi o "REDD+" (Sistema de Redução de Emissões por Desmatamento e Degradação florestal). Com uma dinâmica semelhante à dos créditos de carbono, as unidades da federação que conseguissem diminuir o ritmo da destruição de suas florestas receberiam uma compensação financeira por todo o carbono que deixaram de lançar à atmosfera. Apesar de ser um mecanismo em construção, a Noruega disponibilizou um fundo para a iniciativa no valor de U\$ 2,3 bihões, dentre os quais, 1 bilhão de dólares foram destinados somente à proteção da Amazônia (AZEVEDO et al.: 2012; p.2). Novamente, a lógica de mercado é perceptível.

Finalmente, parece importante ressaltar que recentemente o novo código florestal, Lei 12.651/12, trouxe previsão para a criação e a comercialização de "Cotas de Reservas Ambientais (CRA)". O mecanismo também é simples: todas as reservas florestais das 
propriedades rurais brasileiras passam a ser identificadas e registradas por meio de "cotas". Essas cotas são registradas na matrícula dos imóveis, como representação da área de proteção obrigatória de cada propriedade. Todavia, caso exista em uma propriedade a proteção de mais do que o mínimo legal necessário, seu proprietário poderá vender sua cota, para que ela seja registrada na matrícula de outro imóvel que não preservou o mínimo legal. Como demonstra o art. 48 do novo código florestal: "A CRA pode ser transferida, onerosa ou gratuitamente, a pessoa física ou a pessoa jurídica de direito público ou privado, mediante termo assinado pelo titular da CRA e pelo adquirente."

Essas práticas são importantes para se entender o momento histórico que a ecologia brasileira vem vivendo, um momento de comercialização de cotas de carbono e de REDD+, de cotas de reservas ambientais (CRAs), de preservação da fauna e da flora para receber dividendos de ICMS ecológico, da aquisição de propriedades para a exploração do turismo ecológico. Ano após ano, os valores envolvidos nestes "negócios verdes" têm alcançado marcas históricas no Brasil, atraindo a atenção de investidores de todo o mundo. É também neste mesmo momento que retornam as discussões sobre a possibilidade de aquisição de terras brasileiras por estrangeiros.

Caso as restrições impostas pela Lei 5.709/71 sejam maleabilizadas, ou até mesmo desapareçam, o Brasil se tornará alvo de enviropreneurs de todo o globo, interessados na fatia de um bolo que não para de crescer. Sendo assim, há de se indagar: será que este fenômero será bom para o desenvolvimento brasileiro?

Como já muito se disse, o triunfo das proposições é prático. É certo que a lógica de mercado leva as populações, em alguns casos, a explorarem o meio ambiente de uma forma distinta da tradicionalmente empregada pelos empreendimentos capitalistas, mas até quando este modelo de desenvolvimento econômico é recomendável? François Ost (1997; p. 20-24) diz que a ecologia de livre mercado, em sua essência, é apenas um dos sintomas da crise de representação que atualmente recai sobre o homem. Objetificar e mercantilizar todos os estratos da natureza, submetendo-a às regras do mercado, além de ser uma concepção absurdamente reducionista, é sintoma de uma crise de vínculo entre homem e natureza. Tratar a preservação ambiental como uma questão meramente econômica é o mesmo que afirmar 
que a natureza é um objeto, e pior, com o qual o ser humano não possui ligação.

Em uma época em que se defende uma drástica reforma cultural do modo humano de produzir e modificar o meio ao seu redor (OST: 1997; p. 304-314), muito mais profunda do que a mera implementação do famigerado "desenvolvimento sustentável" (se é que tal coisa é possível), será que a abertura do mercado de terras brasileiro aos adquirentes estrangeiros realmente trará algum benefício duradouro? Se, por um lado, aumentarão o número de reservas florestais nas regiões duramente castigadas pelo desmatamento, por outro, há de se questionar quais serão os benefícios em escala global. Preservar florestas brasileiras para que os países desenvolvidos possam continuar com seu modo insustentável de produção e de emissão de poluentes, é, realmente, uma política adequada de proteção do planeta?

E quais seriam as consequências imediatas dessas políticas para o Brasil? O presidente da Associação Brasileira de Reforma Agrária já manifestou sua opinião (TOLEDO: 2012; p. 4): a reforma agrária será inviabilizada graças à formação de enormes extensões de terras improdutivas, buscando apenas dividendos de créditos de carbono, de reserva florestal e de ICMS ecológico, todavia, perfeitamente defendidas pela Constituição da República por estarem exercendo uma "função socioambiental". Da mesma forma, quais seriam as consequências para a segurança alimentar brasileira? Longe de estimular uma nova forma de se relacionar com a terra, a ecologia de livre mercado busca justamente defender o projeto de desenvolvimento posto, que já demonstrou ser pernicioso. A aquisição de terras brasileiras serviria como uma tentativa de manutenção da forma irracional de produção atualmente praticada. Na melhor das hipóteses, essa forma de ecologia seria mero paliativo para a crise ecológica que, inarredável, bate à porta da humanidade.

E ainda, há de se considerar que nem todos os adquirentes estejam eivados de boa-fé. Na expressão de Vandana Shiva (2001; p. 91-95), o Brasil sabe bem o que é a "pilhagem da natureza e do conhecimento". Sob o manto da atração do investimento, quantos outros cupuaçús serão perdidos?

Do modo como as cartas estão postas, dá-se a entender que as únicas formas que o 
homem conhece de se relacionar com a natureza é por meio de sua completa destruição ou total preservação, o que não parece ser historicamente comprovável. Durante quantos séculos a humanidade foi capaz de tirar seu próprio sustento da terra, sem precisar, para isso, destruíla no processo?

São por esses motivos que as práticas da ecologia de livre mercado, apesar de tentadoras em um primeiro momento, se mostram perniciosas quando entendidas em um contexto global. Além disso, os prejuízos sociais que seriam acarretados são evidentes. O desaparecimento das restrições impostas pelo ordenamento jurídico brasileiro à aquisição de terras por estrangeiros serviria para intensificar essas práticas, não apenas no Brasil, mas em todo o mundo.

\section{Conclusão}

Nas últimas duas décadas o Brasil vem se tornando alvo de políticas de proteção ambiental baseadas em uma lógica de mercado. A corrente, que é chamada de "ecologia de livre mercado", apesar de nunca ter gozado de grande prestígio entre os ecologistas tradicionais, passou a ocupar lugar de grande destaque a partir da década de 90, graças ao triunfo prático de suas proposições.

A ideia deste modelo de ecologia é utilizar os mecanismos de mercado para tornar atrativa a proteção ambiental. As leis da oferta e da procura seriam as únicas verdadeiramente capazes de responder com eficácia e velocidade às questões ambientais. Para tanto, é necessário a existência de três elementos: a objetificação da natureza, ou seja, a transformação em mercadoria de tudo aquilo que é natural, e sua apropriação, a formação de um mercado no qual essa natureza-objeto possa ser livremente comercializada e, finalmente, a ideia de responsabilidade, segundo a qual, cada proprietário, buscando o aumento de seu patrimônio, se tornaria um guardião da natureza, zelando por sua incolumidade.

Dentre os principais instrumentos deste modelo de ecologia, no Brasil, encontramse a comercialização de créditos de carbono e de REDD+, o mecanismo de repasses de ICMS "ecológico", a compra de terras para a formação de unidades privadas de preservação 
ambiental, e, finalmente, a comercialização de "cotas" de reserva ambiental, recente inovação do novo código florestal.

O Brasil vem passando por um momento histórico delicado. As práticas de ecologia de mercado vêm ganhando destaque no país, estimuladas por interessados estrangeiros, no mesmo momento em que também vem crescendo o número de defensores da liberação da aquisição de terras nacionais por estrangeiros, geralmente amparados pela bandeira da atração de investimentos, para os quais a liberação da compra de terras traria um enorme fluxo de investimento para o país, garantindo melhorias econômicas, como o crescimento do PIB, do número de empregos e a modernização do campo.

Como se viu, caso as restrições presentes na Lei 5.709/71 sejam efetivamente revogadas, o Brasil sofrerá com consequências de diversas naturezas. Em primeiro lugar, a utilização das terras brasileiras em um mercado internacional de carbono poderá transformar o país em uma série de imensos latifúndios improdutivos, já que os créditos serão utilizados para subsidiar a atividade industrial internacional. Assim, por exemplo, a reforma agrária se tornaria inviável, uma vez que a propriedade estaria protegida por exercer uma função socioambiental.

Ainda, o Brasil passaria a se tornar um alvo ainda mais frequente da biopirataria. A aquisição de terras em locais de floresta amazônica, por exemplo, poderia servir facilmente de pretexto para a pilhagem dos conhecimentos das sociedades tradicionais indígenas, assim como uma fonte quase inesgotável de patentes de variedades da fauna e da flora.

Ademais, a ecologia de livre mercado levaria o país à contramão do pensamento ecológico contemporâneo, que atualmente prega muito mais do que um pretenso "desenvolvimento sustentável", mas uma verdadeira reforma no modo moderno de se comportar, produzir e consumir. Práticas de mercado serviriam apenas como um paliativo, e, longe de convidar o país a repensar seus hábitos ambientais, na realidade, reforçaria os já existentes. 
Desta forma, é possível afirmar que as restrições trazidas pela Lei 5.709/71 em relação à aquisição de terras por estrangeiros são bastante benéficas ao país, por funcionarem como um sistema de freios aos avanços da ecologia de livre mercado no território nacional.

\section{Referências Bibliográficas}

ANDERSON, Terry L. Environmental Luddites In PERC Reports, Bozeman, v. 30, n. 1, p. 4-5, 2012. Disponível em <www.percreports.org>. Acesso em 05 de janeiro de 2013.

ANDERSON, Terry L.; LEAL, Donald R. Ecologia de Livre Mercado. Trad. Ângela Maria Schmidt Carneiro. Rio de Janeiro: Expressão e Cultura, 1992.

No Longer an Oxymoron. In PERC Reports, Bozeman, v. 18, n. 4, p. 3-5,

Dezembro de 2000. Disponível em <www.percreports.org>. Acesso em 05 de janeiro de 2013.

AZEVEDO, Andrea; NEPSTAD, Daniel; BEZERRA, Thatiana; STABILLE, Marcelo C. C.; MOUTINHO, Fabio; CASTRO, Isabel; LOPES, Ludovino. Mato Grosso no Caminho do Desenvolvimento de baixas emissões: custos e benefícios da implementação do sistema estadual de REDD+. Disponível em: < http://www.ipam.org.br/biblioteca/livro/Mato-Grossono-Caminho-do-Desenvolvimento-de-Baixas-Emissoes-Custos-e-Beneficios-daImplementacao-do-Sistema-Estadual-de-REDD-/682>. Acesso em 13 de janeiro de 2013.

BENJAMIN, Daniel k. Bye Bye Bison. In PERC Reports, Bozeman, v. 30, n. 1, p. 18-20, 2012. Disponível em <www.percreports.org>. Acesso em 05 de janeiro de 2013.

BRASIL. Advocacia-Geral da União. Parecer n. GQ-181, de 17 de dezembro de 1998. 1. A conclusão do Parecer $n^{\circ}$ AGU/LA-04/94, relativa à revogação do $\S 1^{\circ}$ do art. $1^{\circ}$ da Lei ${ }^{\circ}$ 5.709, de 7 de outubro de 1971, permanece inalterada, apesar da revogação do art. 171 da Constituição de 1988. 2. Possibilidade de legislação infraconstitucional futura, em razão de fundamentos relevantes, impor limitações ao capital estrangeiro em determinados casos. Advogado-Geral: Geraldo Magela da Cruz Quintão. Diário Oficial da República Federativa do Brasil, Brasília, 21 jan. 1999.

Advocacia-Geral da União. Parecer n. LA-01, de 19 de agosto de 2010. Aquisição de terras por estrangeiros. Revisão do Parecer GQ-181, de 1998, publicado no Diário Oficial em 22.01.99, e GQ-22, de 1994. Recepção do $§ 1^{\circ}$ do art. $1^{\circ}$ da Lei $n^{\circ} 5.709$, de 1971, à luz da Constituição Federal de 1988. Equiparação de empresa brasileira cuja maioria do capital social esteja nas mãos de estrangeiros não-residentes ou de pessoas jurídicas estrangeiras não autorizadas a funcionar no Brasil a empresas estrangeiras. Advogado-Geral: Luís Inácio Lucena Adams. Diário Oficial da República Federativa do Brasil, Brasília, 23 ago. 2010.

CYSNEIROS, Vicente Cavalcanti. Aquisição de imóvel rural por estrangeiros. Brasília: Fundação Petrônio Portella, 1982.

FALQUE, Max. Les droits de propriété au cœur de la protection environnementale: le 
problème de la biodiversité. Nomos: Revista do Programa de Pós-Graduação em Direito da UFC, Fortaleza, Vol. 30, n.1, p. 201-212, jan/jun 2010.

FERREIRA, Venilson. Lei que restringe compra de terras por estrangeiros será revista. Jornal Estado de São Paulo, São Paulo, 31 de outubro de 2012. Disponível em:

$<$ http://www.estadao.com.br/noticias/nacional,lei-que-restringe-compra-de-terra-porestrangeiros-sera-revista,954001,0.htm> Acesso: 13 de janeiro de 2013.

HARDIN, Garrett. The Tragedy of the Commons. Science: New Series, Stanford, v. 162, n. 3859, p. 1243-1248, Dezembro de 1968.

JORDÃO, Luciana Ramos. Da questão agrária e da aquisição de terras por estrangeiros. Goiânia, 2012. Dissertação (mestrado em direito agrário), Universidade Federal de Goiás, Faculdade de Direito.

LEPAGE, Henri. Pourquoi la propriété. Paris: Hachette, 1985. Col. Pluriel.

OLIVEIRA, A. U. A questão da aquisição de terras por estrangeiros no Brasil - um retorno aos dossiês. In Agrária, São Paulo, n. 12, p. 3-113, 2010. Disponível em:

<http://www.geografia.fflch.usp.br/revistaagraria/index.htm>. Acesso em 13 de janeiro de 2013.

OST, François. A Natureza à Margem da Lei: a Ecologia à Prova do Direito. Trad. Joana Chaves. Lisboa: Instituto Piaget, 1997.

PLATTS, Linda E. Predator free Possums meet Co2 Powered Piston. In PERC Reports, Bozeman, v. 30, n. 1, p. 37, 2012. Disponível em 〈www.percreports.org〉. Acesso em 05 de janeiro de 2013.

REGAN, Shawn. The secret life of trees: how pens are preserving old-groth forests. In PERC Reports, Bozeman, v. 30, n. 1, p. 12-17, 2012. Disponível em <www.percreports.org>. Acesso em 05 de janeiro de 2013.

SHIVA, Vandana. Biopirataria: a pilhagem da natureza e do conhecimento. Trad. Laura Cardellini Barbosa de Oliveira. Petrópolis: Vozes, 2001.

TOLEDO, Virginia. Liberar compra de terra para estrangeiro favorece 'ambientalistas de mercado'. In Rede Brasil Atual, São Paulo, 21 de julho de 2012. Disponível em: <http://www.redebrasilatual.com.br/temas/cidadania/2012/07/lei-que-libera-compra-de-terrapara-estrangeiro-favorece-ambientalistas-de-mercado>. Acesso em: 13 de janeiro de 2013.

WATSON, Reed. The underwater enviropreneur. In PERC Reports, Bozeman, v. 30, n. 1, p. 20-25, 2012. Disponível em <www.percreports.org>. Acesso em 05 de janeiro de 2013.

\footnotetext{
1 "We can make little progress in working towards optimum population size until we explicitly exorcize the spirit of Adam Smith in the field of practical demography." (HARDIN: 1968; p.1244).
} 
${ }^{2} \mathrm{Na}$ concepção do próprio autor (HARDIN: 1968; 1243), a ideia de que os recursos naturais são finitos, e que

este problema não comporta soluções meramente técnicas, ganhou força a partir das proposições de Malthus.

3 “A finite world can support only a finite population;" (HARDIN: 1968; p.1243).

4 "And thus, just as the market brought the bison to near extinction, so too has it brought them back from the brink." (BENJAMIN: 2012; p. 20).

5 "Others have turned to market solutions simply because nothing else has worked. "It's very hard to make progress through lawsuits," says Bill Heddon of Grand Canyon Trust, an organization that is trying to improve the quality of grazing lands in the West" (ANDERSON; LEAL: 2000; p.3).

6 Dados obtidos no sítio eletrônico da instituição: <http://www.nature.org/about-us/private-landsconservation/index.htm.> Acesso em 06 de janeiro de 2013.

${ }_{8}^{7}$ Os números da revista desde 1997 estão disponíveis no sítio eletrônico: <www.percreports.org>
Dados $\begin{array}{ll}\text { disponíveis } \\ \text { em: }\end{array}$ <http://www.camara.gov.br/proposicoesWeb/fichadetramitacao?idProposicao=373948>. Acesso em 13 de janeiro de 2013.

${ }^{9}$ Conformes os dados do sítio eletrônico da instituição: < http://www.nature.org/about-us/private-landsconservation/index.htm>. Acesso em 13 de janeiro de 2013.

${ }^{10}$ Neste $\quad$ sentido: <http://portugues.tnc.org/tnc-no-mundo/americas/brasil/iniciativas/areasprotegidas/index.htm>. Acesso em 13 de janeiro de 2013.

${ }^{11}$ De acordo com dados do sítio eletrônico <www.icmsecologico.com.br>. Acesso em 13 de janeiro de 2013. Apontado como oficial pelo sítio da Natural Conservancy. 2013.

${ }^{12}$ De acordo com dados do sítio eletrônico <www.icmsecologico.com.br>. Acesso em 13 de janeiro de 